\title{
Feasibility of Neurorehabilitation Using a Hybrid Assistive Limb for Patients Who Underwent Spine Surgery
}

\author{
Aya Yatsugi, ${ }^{1,2}$ Takashi Morishita $\left(D,{ }^{1}\right.$ Hiroyuki Fukuda, ${ }^{1,2}$ Naoya Kotani, ${ }^{2}$ Kenji Yagi, \\ Hiroshi Abe, ${ }^{1}$ Etsuji Shiota, ${ }^{2}$ and Tooru Inoue ${ }^{1}$ \\ ${ }^{1}$ Department of Neurological Surgery, Fukuoka University Faculty of Medicine, Fukuoka, Japan \\ ${ }^{2}$ Department of Rehabilitation Medicine, Fukuoka University Hospital, Fukuoka, Japan \\ Correspondence should be addressed to Takashi Morishita; tmorishita@fukuoka-u.ac.jp
}

Received 17 February 2018; Revised 21 May 2018; Accepted 19 June 2018; Published 10 July 2018

Academic Editor: Liwei Shi

Copyright (c) 2018 Aya Yatsugi et al. This is an open access article distributed under the Creative Commons Attribution License, which permits unrestricted use, distribution, and reproduction in any medium, provided the original work is properly cited.

\begin{abstract}
Recent studies of robotic rehabilitation have demonstrated its efficacy for neurological disorders. However, few studies have used the Hybrid Assistive Limb (HAL) during the early postoperative stage of spine disorders. We aimed to evaluate the safety and efficacy of HAL treatment during the early postoperative period for spine disorder patients. We retrospectively identified patients who underwent spine surgery and who could complete HAL treatment. We evaluated the 10-m walking test (10MWT), the modified Gait Abnormality Rating Scale (GARS-M), Barthel Index (BI), and the walking index for spinal cord injury II (WISCI II) score results before and after robotic rehabilitation. Clinical outcomes were compared after treatment. We included nine patients with various spine problems. After HAL treatment, the speed during the 10MWT significantly improved from $64.1 \pm 16.0$ to $74.8 \pm 10.8 \mathrm{~m} / \mathrm{min}$, and the walking cadence decreased from $102.7 \pm 17.6$ to $92.7 \pm 10.9$ steps $/ \mathrm{min}$. The BI score also improved from $83.3 \pm 16.0$ to $95.6 \pm 5.8$, and the WISCI II score improved from $19.7 \pm 0.5$ to $20.0 \pm 0.0$. Furthermore, the total GARS-M score improved from $6.0 \pm 5.7$ to $2.3 \pm 3.3$. The maximum angles of the trunk swing were improved from $2.2 \pm 1.9$ to $1.2 \pm 0.9$ degrees. Neurorehabilitation therapy using HAL for spinal surgery patients was considered feasible following spine surgery.
\end{abstract}

\section{Introduction}

Robotic technologies have been increasingly gaining attention in the field of neurorehabilitation. The Hybrid Assistive Limb (HAL) (Cyberdyne Inc., Ibaraki, Japan) is a unique exoskeleton robot for neurorehabilitation that was developed by Sankai and colleagues based on the interactive biofeedback (iBF) theory $[1,2]$. HAL has a hybrid system that allows both voluntary and autonomous modes of action to support training, and it supports voluntary muscle movement by detecting bioelectrical signals (BES). For walking training, movements of the joints are accurately adjusted by the pressure sensor in the foot bottom and joint angle sensors of the frame. Based on the input information, four actuators of the hip and knee joint are controlled independently [3]. Movements of the affected limbs supported by the HAL system generate sensory feedback to the brain (i.e., iBF) and accelerate motor learning in the process of functional recovery.

Recent studies have shown the safety and efficacy of rehabilitation using HAL robotics for various disorders, including stroke [3-7], spinal cord injury (SCI) [8-14], and quadriceps arthrogenic muscle inhibition [15]. Another recent study demonstrated neuroplasticity induced by HAL treatment $[16,17]$. However, five case reports have focused on the efficacy of HAL therapy for postoperative thoracic ossification of the posterior longitudinal ligament (OPLL) [18-22]. These reports indicated that HAL was used as a last resort for gait recovery during the almost chronic phase of the postoperative state $[21,22]$, and the authors recommended starting HAL-assisted training during the early stage following surgery. Neurorehabilitation during the postoperative state is essential for returning to social activities and preventing 
disuse syndrome. Based on the findings indicated by these five case reports [18-22], in addition to the reports demonstrating the efficacy of HAL training for SCI cases [8-14], we hypothesized that using HAL may facilitate early recovery after spine surgery. Therefore, we aimed to evaluate the safety and efficacy of HAL-assisted rehabilitation for spine disorder patients during the early postoperative period.

\section{Materials and Methods}

2.1. Patient Selection and Study Design. We performed a retrospective chart review of patients with spine disorders treated at our neurosurgical department from October 2011 to February 2016. To evaluate the effects of HAL treatment for improvements in gait, we included patients who could complete HAL treatment at least three times. Additionally, because voluntary muscle contractions are required to gain assistance from the HAL system, we excluded patients with complete or nearly complete paralysis. The protocol of the present study was approved by our institutional review board (IRB), and HAL treatment was performed after receiving written informed consent from each patient.

HAL treatment was performed for 31 patients with spine disorders; however, 22 patients did not meet the inclusion criteria of the current study (Figure 1). Among those 22 patients, 13 did not undergo surgery.

We investigated the remaining nine patients (six male patients and three female patients) with the following characteristics: severe impairment resulting in the inability to use HAL $(n=5)$ and less than three sessions of HAL treatment $(n=4)$. The mean age of the cohort was 53.6 years (SD, \pm 16.1$)$. Diagnoses were dural arteriovenous fistula (AVF) $(n=2)$, cervical ossification of the posterior longitudinal ligament (OPLL) $(n=1)$, spinal lipoma $(n=1)$, arachnoid cyst $(n=1)$, spinal ependymoma $(n=3)$, and cervical spondylosis $(n=1)$. Spine lesion levels are summarized in Table 1.

2.2. Rehabilitation Program. We performed conventional physical therapy in addition to HAL treatment. Conventional physical therapy started within 2 days after surgery. Depending on the patient's condition, the programs included manual leg stretching, muscular workouts, and basic movement training such as standing, walking, and going up and down stairs. When patients felt fatigue during the HAL treatment, they were allowed to rest. Each session lasted approximately 50 minutes, including time necessary for robotic attachment, and was performed two or three times per week.

HAL treatment started when the patients were able to sit stably. On average, intervention with therapists and HAL treatment began 14.2 \pm 8.1 days (range 7-29 days) after surgery. The mean number of HAL treatment sessions was $5.0 \pm 2.6$ (range 3-12). Rehabilitation periods comprised $13.6 \pm 9.1$ days (range 4-35 days) during hospitalization at our institution (Table 1).

A bilateral leg version of HAL was used for patients involved in this study (HAL for Living Support-Lower Limb; Cyberdyne Inc.). Training started with the Cybernic Voluntary Control mode, which measures BES from the extensor and flexor muscles of the hip and knee. HAL treatment was

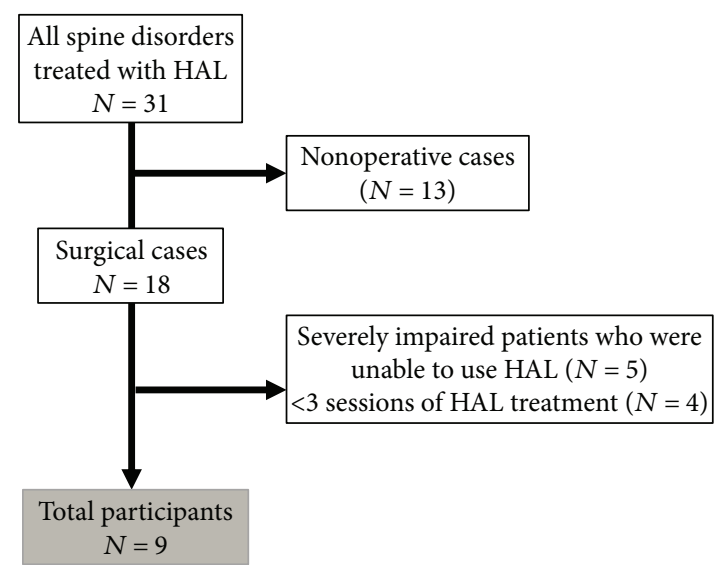

FIgURE 1: Patient selection flowchart.

performed by one or two physiotherapists and a medical doctor who were trained to use the HAL system. During gait training, the physiotherapist checked the BES and adjusted the HAL assist level.

During HAL treatment, several sets of a knee extension movement were performed (10 times with the left leg and 10 times with the right leg). The standing movement was performed 10 times. Balance training was performed for several seconds with open eyes or closed eyes so that the center of gravity would be in the middle. Finally, walking training was performed on a flat ground or a treadmill. During balance training and gait training, we used a monitor displayed in front of the patient to provide visual feedback regarding the center of gravity, posture, and balance (Figure 2).

We focused on walking training. We used a walk aid called All-In-One Walking Trainer (Ropox A/S, Naestved, Denmark) to secure the safety of patients when walking on a flat floor. It is able to support body weight and enables safe HAL treatment with the use of a harness. We did not use body weight support. After the patient became accustomed to walking on the ground, we began treadmill walking. Patients performed several sets of 5 minutes of walking at a speed that was comfortable with HAL. If patients wanted to continue and were not fatigued, then we increased the speed or increased the walking time. When there was deflection of the center of gravity (it does not take weight to walk on tiptoes), we instructed the patient to move the weight from the heel to the tiptoes.

2.3. Outcome Measures. All patients were video-recorded during rehabilitation. The speed and steps during the $10-\mathrm{m}$ walking test (10MWT) as an evaluation of motor function at the time of treatment immediately before wearing HAL and during the last training session after excluding HAL were used to evaluate HAL treatment times. We used the modified Gait Abnormality Rating Scale (GARS-M) [23], the Barthel Index (BI), and the walking index for spinal cord injury II (WISCI II) to evaluate walking appearance, activities of daily living (ADL), and the patients' ambulatory walking capacity on the basis of the need for physical assistance and assistive devices, respectively [24]. The GARS-M includes variables that provide a description of gait associated with an increased 
TABle 1: Patient characteristics.

\begin{tabular}{|c|c|c|c|c|c|c|c|}
\hline Patient & Age (years) & Sex & Diagnosis & Lesion level & $\begin{array}{l}\text { Surgery-HAL } \\
\text { interval (days) }\end{array}$ & $\begin{array}{c}\text { Number of HAL } \\
\text { sessions }\end{array}$ & $\begin{array}{l}\text { Rehabilitation } \\
\text { period (days) }\end{array}$ \\
\hline 1 & 48 & Male & Arachnoid cyst & C5-Th1 & 7 & 3 & 7 \\
\hline 2 & 65 & Male & Dural AVF & Th6-7 & 13 & 12 & 35 \\
\hline 3 & 56 & Male & Dural AVF & Th6-7 & 10 & 3 & 4 \\
\hline 4 & 70 & Male & Cervical OPLL & C2-Th1 & 14 & 5 & 9 \\
\hline 5 & 67 & Male & Spinal lipoma & $\mathrm{L} 2-5$ & 21 & 5 & 7 \\
\hline 6 & 72 & Male & Cervical spondylosis & $\mathrm{C} 4-5$ & 11 & 5 & 10 \\
\hline 7 & 29 & Female & Spinal ependymoma & C6 & 29 & 4 & 18 \\
\hline 8 & 36 & Female & Spinal ependymoma & $\mathrm{C} 2-3$ & 14 & 3 & 21 \\
\hline 9 & 39 & Female & Spinal ependymoma & Medulla oblongata to Th1 & 19 & 5 & 11 \\
\hline Mean \pm SD & $53.6 \pm 16.1$ & & & & $14.2 \pm 8.1$ & $5.0 \pm 2.6$ & $13.6 \pm 9.1$ \\
\hline
\end{tabular}

$\mathrm{AVF}=$ arteriovenous fistula; $\mathrm{OPLL}=$ ossification of the posterior longitudinal ligament; $\mathrm{SD}=$ standard deviation .

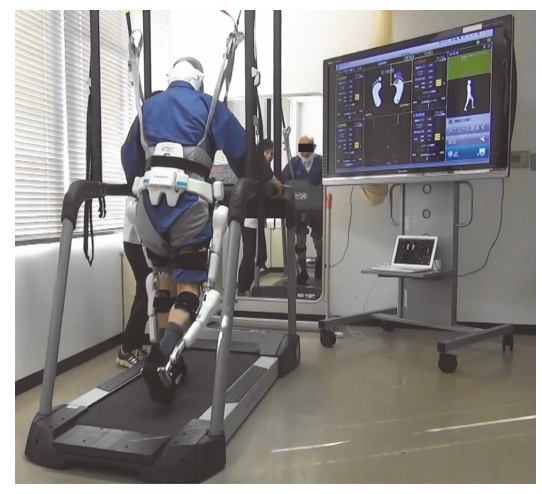

(a)

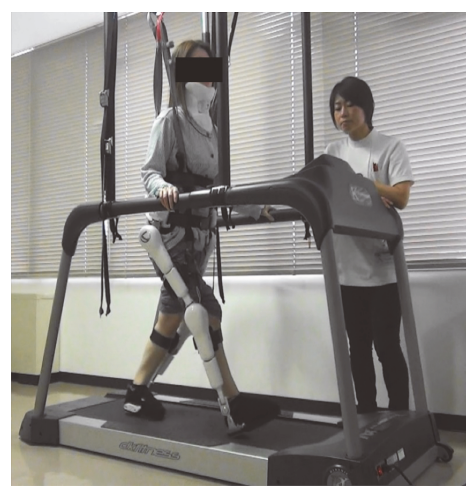

(b)

Figure 2: $(\mathrm{a}, \mathrm{b})$ Hybrid Assistive Limb (HAL) treatment. Gait training on a treadmill in front of a large monitor.

risk of falling. The GARS-M considered the following seven items: (1) variability, (2) guardedness, (3) staggering, (4) foot contact, (5) hip range of motion (ROM), (6) shoulder extension, and (7) arm-heel strike synchrony. Each item of the GARS-M is rated from 0 to 3 , with a maximum of 21 points; a score of 21 points indicates the worst state. We measured the maximum angle of the trunk swing during the 10MWT before and after treatment using the Total Motion Coordinate System version 3.28 (Toso System Inc., Tokyo, Japan) motion analysis device.

2.4. Statistical Analysis. We performed a paired $t$-test to compare the clinical outcomes and baseline. We used SPSS version 21.0 (IBM Corp., Armonk, NY, USA) for the analyses. The mean \pm SD values are described.

\section{Results}

After HAL treatment, the speed during the 10MWT significantly improved from $64.1 \pm 16.0$ to $74.8 \pm 10.8 \mathrm{~m} / \mathrm{min}$ $(P=0.031)$, and the cadence decreased from $102.7 \pm 17.6$ to $92.7 \pm 10.9$ steps $/ \mathrm{min}(P=0.046)$. The BI score also improved from $83.3 \pm 16.0$ to $95.6 \pm 5.8(P=0.043)$. Furthermore, the total GARS-M score improved from $6.0 \pm 5.7$ to $2.3 \pm 3.3$ $(P=0.005)$. The maximum angles of the trunk swing were improved from $2.2 \pm 1.9$ to $1.2 \pm 0.9$ degrees $(P=0.033)$.
The WISCI II score also improved from $19.7 \pm 0.5$ to $20.0 \pm 0.0 \quad(P=0.081)$. These scores are summarized in Figure 3. There were no adverse events due to HAL treatment such as pain and/or falling.

It is noteworthy that almost all subjects had improved gait posture. After reviewing each item before and after HAL treatment, it became clear that the subscores of guardedness (item 2), staggering (item 3), and shoulder extension (item 6) showed the most dramatic improvements. Momentum and the ability to move the legs forward were improved. Collapse of balance toward the side was decreased. The movement range of the shoulder toward the backside was expanded.

3.1. Representative Case (Case 2). A 65-year-old man was diagnosed with dural AVF at the level of Th6-7 and underwent laminectomy for ligation of the draining vein. Preoperatively, he had urinary continence and was wheelchair-bound. A few days after surgery, conventional physical therapy was started and his walking ability gradually improved so that he could walk with an aid on postoperative day 9. However, his gait posture had involved sweeping out his lower limbs at the cost of laterally bending the trunk to the opposite side (Figure 4). He also had difficulty in kicking the ground with the toes. 

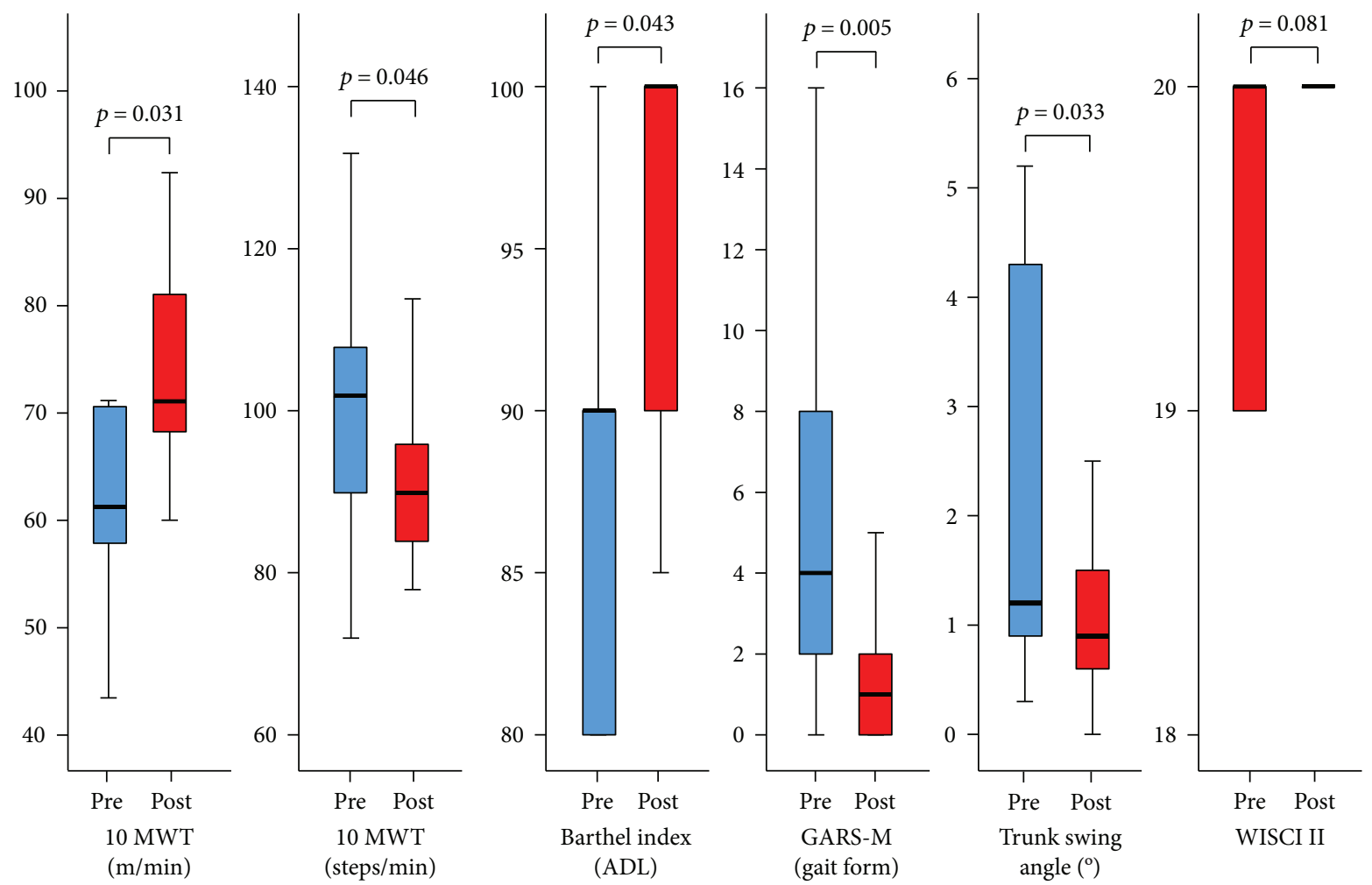

FIGURE 3: Graph showing functional outcomes evaluated by the $10-\mathrm{m}$ walking test (10MWT): speed ( $\mathrm{m} / \mathrm{min})$, cadence (steps/min), the Barthel Index, modified Gait Abnormality Rating Scale (GARS-M), trunk swing angle before and after Hybrid Assistive Limb (HAL) treatment, and the walking index for spinal cord injury II (WISCI II) score. Whiskers represent the standard deviation. Pre: before treatment; Post: after treatment.

We started using HAL on postoperative day 13. At this point, his WISCI II score was 19. At first, he performed knee extension movements and standing training. Next, he started balance training and gait training with a walking device (All-In-One Walking Trainer; Ropox A/S). Later, walking training on a treadmill was initiated.

Before HAL treatment, his trunk was bending forward and he required walking support. After 12 sessions of HAL treatment, the trunk lifted while walking and posture improved. He could constantly set the position of his foot and the step width. He became able to kick the ground on tiptoes and swing out his lower limbs without side bending of the trunk. The angle of his trunk swing during 10MWT decreased from 4.6 to 1.4 degrees (Figure 4). His 10MWT speed improved from 43.4 to $65.7 \mathrm{~m} / \mathrm{min}$, and the walking cadence decreased from 132 to 96 steps $/ \mathrm{min}$. The total GARS-M score improved from 16 to 10 . Similarly, the BI and WISCI II score improved from 55 to 100 and from 19 to 20 , respectively.

\section{Discussion}

The HAL was invented based on the iBF theory $[1,2]$ that movements of the affected limbs supported by the HAL system generate sensory feedback to the brain (i.e., iBF) and accelerate motor learning in the process of functional recovery. HAL therapy may address spasticity due to central nervous system (CNS) lesions. A CNS lesion above the

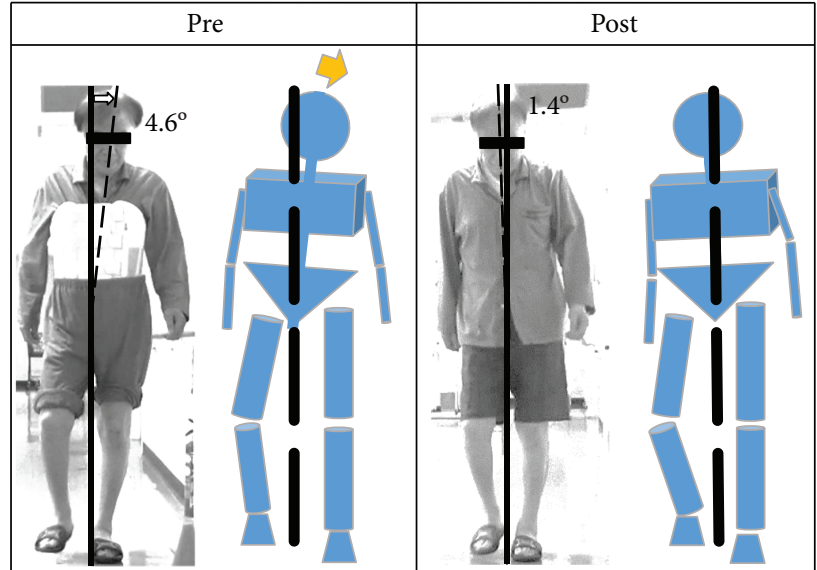

FIGURE 4: Representative case showing improvements in walking appearance. Prior to Hybrid Assistive Limb (HAL) treatment, the trunk leaned toward the left when standing with the left leg. Furthermore, the trunk was leaned $4.6^{\circ}$ to the left. After 12 sessions of HAL treatment, the upper body was stabilized. Pre: before training; Post: after training.

level of the central pattern generator (CPG) results in a loss of supraspinal drive and spasticity. The consequences are hyperexcitability of short-latency reflexes, loss of longlatency reflexes, and changes in muscle properties [25]. According to the iBF theory, sensory input is sent back to the CNS to activate the impaired neuronal networks 


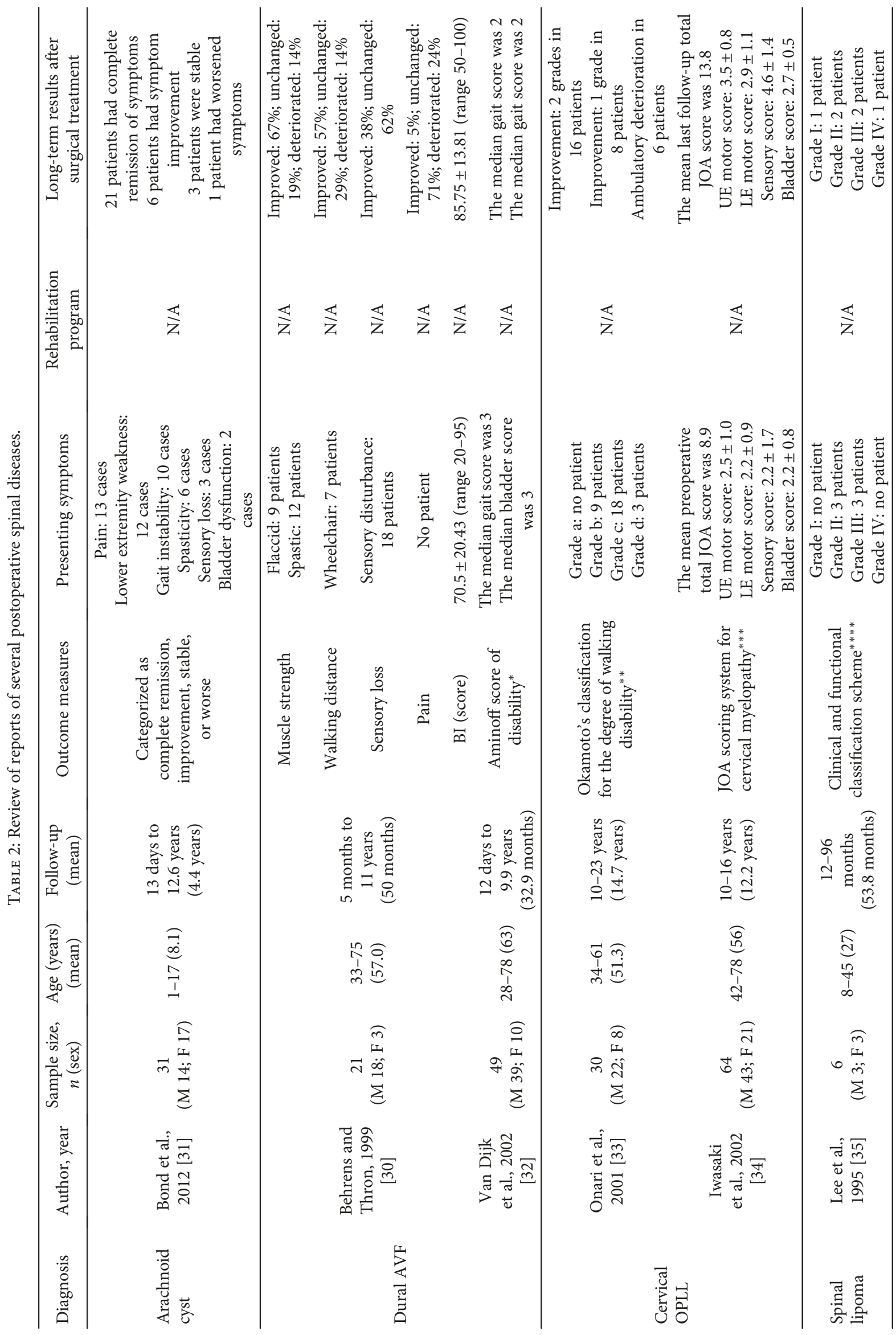




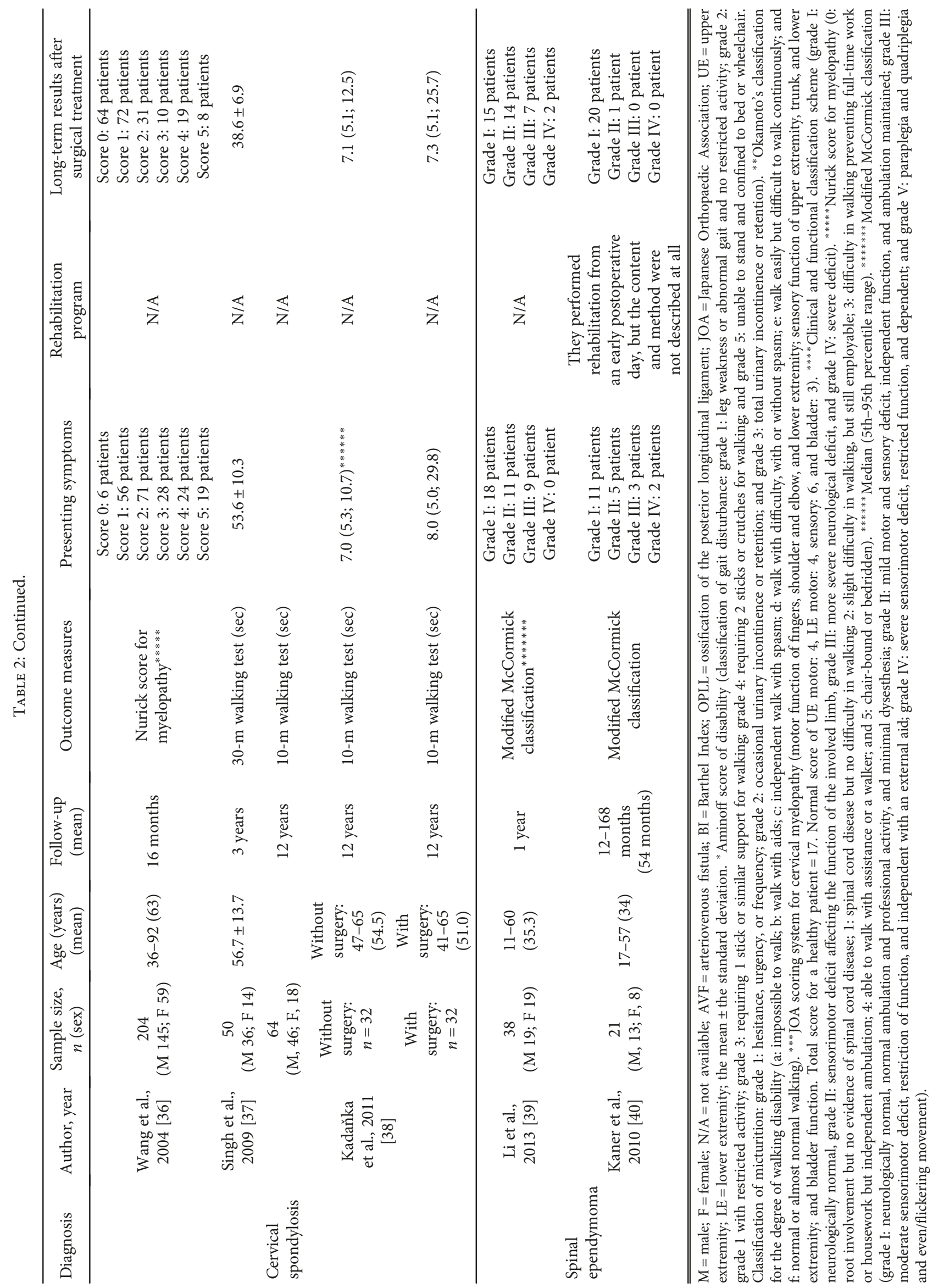




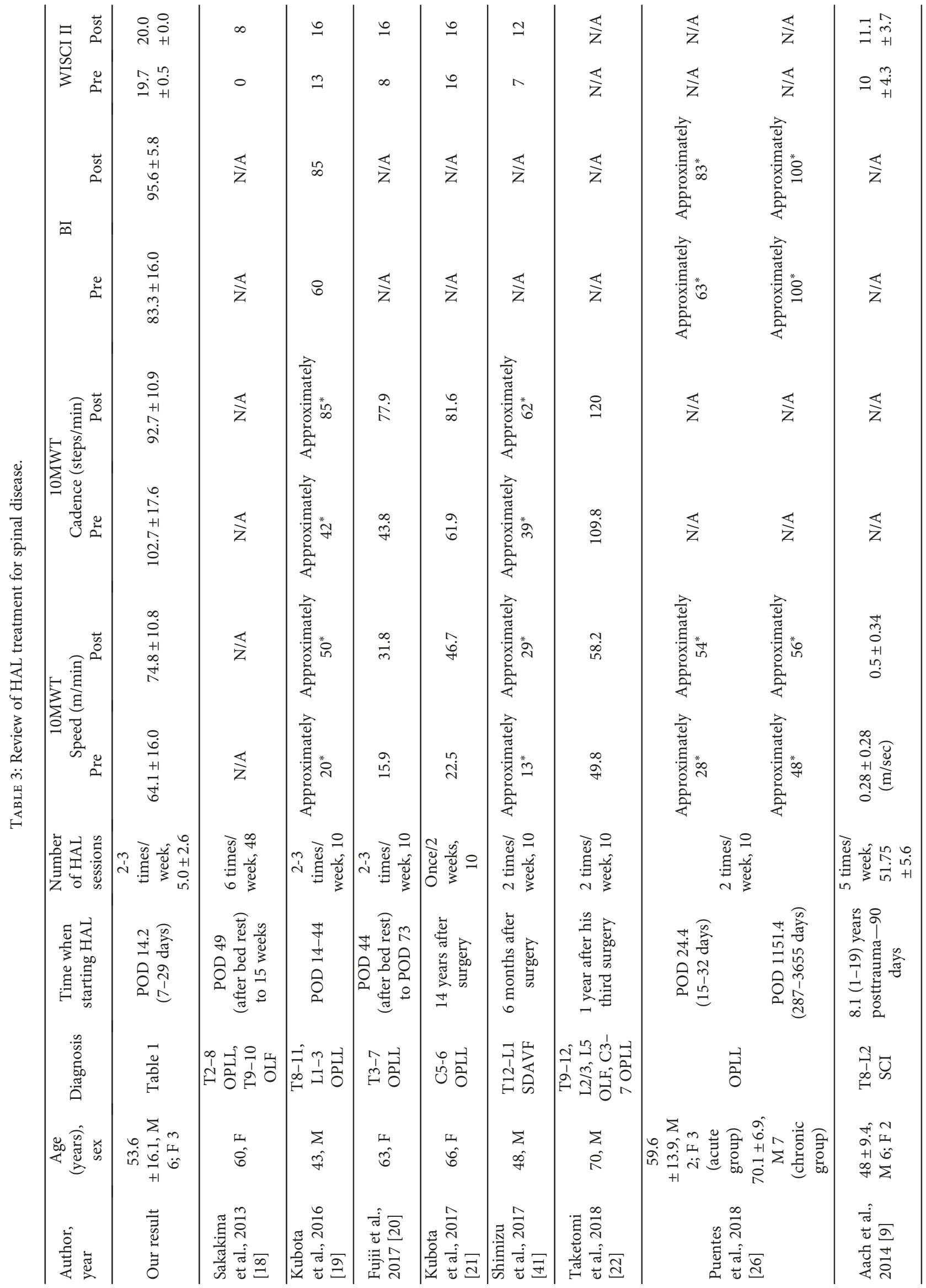




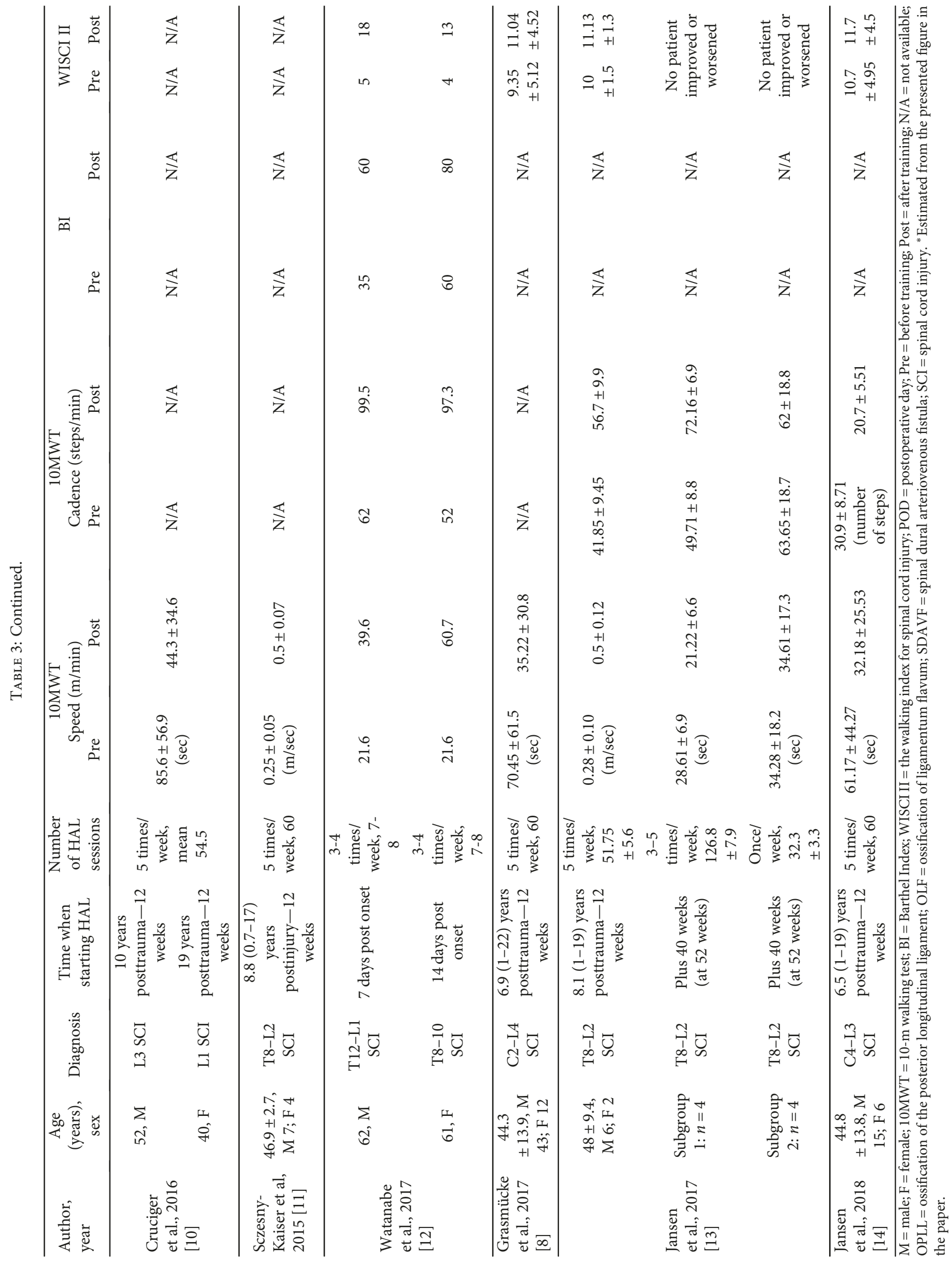


(biofeedback); in turn, the activated CNS enhances its descending signals [2]. Therefore, the spasticity could be ameliorated by HAL therapy. Furthermore, a previous study showed that HAL was effective for treating spastic hemiplegia due to stroke [16], and two studies have shown that HAL treatment for stroke patients facilitated cortical activities in the damaged brain $[16,17]$.

In this study, significant improvements were seen in gait ability following robotic rehabilitation. The results showed improvements in a series of clinical scales such as 10MWT, BI, GARS-M, and WISCI II. All participants showed improvements in gait ability that were similar to those of previous reports concerning the use of HAL for spine disorders such as SCI [8-14], SDAVF [41], and OPLL $[18-22,26]$. It is noteworthy that participants in our study underwent surgery for various reasons such as spinal cord tumor, vascular disease, and bone degenerative disease. Additionally, clinical manifestations of vascular disease and tumors in the spine are similar [27, 28], and rehabilitation outcomes following vascular-related and traumatic SCI were reportedly not significantly different [29]. These facts may indicate that HAL therapy may be applied for a variety of disorders with spinal cord origins.

This study also showed the usefulness of HAL for postoperative rehabilitation. There have been only five case reports of HAL-assisted rehabilitation for a patient who underwent surgery for thoracic OPLL [18-22]. It is advantageous that HAL does not interfere with the skin incision and can be used for patients with a corset. In our experience, HAL was considered to facilitate early recovery after spine surgery.

In this study, HAL treatment was performed for patients with rare spinal diseases. In previous studies, the diagnosis and surgical management were emphasized rather than the rehabilitation programs, even though it has been considered that improvement after surgery depends on the length of time and initiation of neurological rehabilitation [30]. However, outcome measures have not been standardized. Previous reports showing the clinical outcomes of treatment for the same spine disorders are summarized in Table 2 [30-40].

We also reviewed clinical studies of gait training using HAL for spine disorders. A systematic search of the literature was conducted using the PubMed database. Search terms were "HAL" OR "Hybrid Assistive Limb" AND "Spinal Cord Injury" OR "OPLL." We searched Google Scholar, and only one work [19] was included from that search. Studies only reporting HAL for gait training were included. Of 20 literatures, six were excluded due to the difference in the type of HAL robot. Overall, 14 studies met the inclusion criteria and were subject to critical review (Table 3) [8-14, 18-22, 26, 41].

Results of the systematic review revealed that HAL treatment was performed mainly for spinal cord injury and degenerative disease at various stages of disorders. Overall, these previous reports $[12,13,19-22,41]$ showed that both the speed and cadence were increased compared with our results. We considered the difference in the change in the gait speed. Previous reports $[12,13,19-22,41]$ indicated that more steps increased the cadence, whereas our results indicated that long steps decreased the cadence. Although natural recovery in the acute state following injury or surgical intervention has to be taken into account, it was thought that the functional recovery rate could be facilitated by HAL treatment from an early stage [18-20, 26].

Even though our study showed a significant improvement with HAL treatment, it had several limitations. We investigated a relatively small number of patients with heterogeneous characteristics. Our patients underwent HAL treatment during the early postoperative state, but our cohort did not have a control group. Therefore, it is possible that spontaneous recovery following surgery may have contributed to the postoperative course. However, it should also be noted that our patients experienced earlier recovery than those described in previous reports $[18-20,26]$ because our patients started HAL therapy during relatively early postoperative periods.

\section{Conclusions}

We showed the feasibility and safety of HAL treatment and determined that it could potentially facilitate functional recovery, even for postoperative patients. Further studies involving more patients and a control group are warranted to verify our findings.

\section{Data Availability}

The data used to support the findings of this study are available from the corresponding author upon request.

\section{Conflicts of Interest}

The authors declare that they have no conflicts of interest.

\section{Acknowledgments}

This study was partly supported by the Japan Society for the Promotion of Science grant-in-aid for young scientists ((B) 15 K19984); Takeda Science Foundation, Uehara Memorial Foundation; and Central Research Institute, Fukuoka University (Grant no. 161042). The authors appreciate the help of Ms. Asuka Ikezaki, who assisted with the statistical analysis.

\section{References}

[1] K. Suzuki, G. Mito, H. Kawamoto, Y. Hasegawa, and Y. Sankai, "Intention-based walking support for paraplegia patients with robot suit HAL," Advanced Robotics, vol. 21, no. 12, pp. 14411469, 2007.

[2] T. Morishita and T. Inoue, "Interactive bio-feedback therapy using hybrid assistive limbs for motor recovery after stroke: current practice and future perspectives," Neurologia MedicoChirurgica, vol. 56, no. 10, pp. 605-612, 2016.

[3] H. Kawamoto, S. Taal, H. Niniss et al., "Voluntary motion support control of robot suit HAL triggered by bioelectrical signal for hemiplegia," in 2010 Annual International Conference of the IEEE Engineering in Medicine and Biology, pp. 462-466, Buenos Aires, Argentina, 2010. 
[4] T. Ueba, O. Hamada, T. Ogata, T. Inoue, E. Shiota, and Y. Sankai, "Feasibility and safety of acute phase rehabilitation after stroke using the Hybrid Assistive Limb robot suit," Neurologia Medico-Chirurgica, vol. 53, no. 5, pp. 287-290, 2013.

[5] H. Fukuda, T. Morishita, T. Ogata et al., "Tailor-made rehabilitation approach using multiple types of Hybrid Assistive Limb robots for acute stroke patients: a pilot study," Assistive Technology, vol. 28, no. 1, pp. 53-56, 2016.

[6] H. Fukuda, K. Samura, O. Hamada et al., "Effectiveness of acute phase Hybrid Assistive Limb rehabilitation in stroke patients classified by paralysis severity," Neurologia MedicoChirurgica, vol. 55, no. 6, pp. 487-492, 2015.

[7] T. Ogata, H. Abe, K. Samura et al., "Hybrid Assistive Limb (HAL) rehabilitation in patients with acute hemorrhagic stroke," Neurologia Medico-Chirurgica, vol. 55, no. 12, pp. 901-906, 2015.

[8] D. Grasmücke, A. Zieriacks, O. Jansen et al., "Against the odds: what to expect in rehabilitation of chronic spinal cord injury with a neurologically controlled Hybrid Assistive Limb exoskeleton. A subgroup analysis of 55 patients according to age and lesion level," Neurosurgical Focus, vol. 42, no. 5, p. E15, 2017.

[9] M. Aach, O. Cruciger, M. Sczesny-Kaiser et al., "Voluntary driven exoskeleton as a new tool for rehabilitation in chronic spinal cord injury: a pilot study," The Spine Journal, vol. 14, no. 12, pp. 2847-2853, 2014.

[10] O. Cruciger, T. A. Schildhauer, R. C. Meindl et al., "Impact of locomotion training with a neurologic controlled Hybrid Assistive Limb (HAL) exoskeleton on neuropathic pain and health related quality of life (HRQoL) in chronic SCI: a case study," Disability and Rehabilitation. Assistive Technology, vol. 11, no. 6, pp. 529-534, 2016.

[11] M. Sczesny-Kaiser, O. Hoffken, M. Aach et al., "HAL ${ }^{\circledR}$ exoskeleton training improves walking parameters and normalizes cortical excitability in primary somatosensory cortex in spinal cord injury patients," Journal of Neuroengineering and Rehabilitation, vol. 12, no. 1, p. 68, 2015.

[12] H. Watanabe, A. Marushima, H. Kawamoto et al., "Intensive gait treatment using a robot suit Hybrid Assistive Limb in acute spinal cord infarction: report of two cases," The Journal of Spinal Cord Medicine, pp. 1-7, 2017.

[13] O. Jansen, T. A. Schildhauer, R. C. Meindl et al., "Functional outcome of neurologic-controlled HAL-exoskeletal neurorehabilitation in chronic spinal cord injury: a pilot with one year treatment and variable treatment frequency," Global Spine Journal, vol. 7, no. 8, pp. 735-743, 2017.

[14] O. Jansen, D. Grasmuecke, R. C. Meindl et al., "Hybrid Assistive Limb exoskeleton HAL in the rehabilitation of chronic spinal cord injury: proof of concept; the results in 21 patients," World Neurosurgery, vol. 110, pp. e73-e78, 2018.

[15] K. Goto, T. Morishita, S. Kamada et al., "Feasibility of rehabilitation using the single-joint Hybrid Assistive Limb to facilitate early recovery following total knee arthroplasty: a pilot study," Assistive Technology, vol. 29, no. 4, pp. 197-201, 2016.

[16] K. Saita, T. Morishita, K. Hyakutake et al., "Combined therapy using botulinum toxin $\mathrm{A}$ and single-joint Hybrid Assistive Limb for upper-limb disability due to spastic hemiplegia," Journal of the Neurological Sciences, vol. 373, pp. 182-187, 2017.

[17] K. Saita, T. Morishita, H. Arima et al., "Biofeedback effect of Hybrid Assistive Limb in stroke rehabilitation: a proof of concept study using functional near infrared spectroscopy," PLoS One, vol. 13, no. 1, article e0191361, 2018.

[18] H. Sakakima, K. Ijiri, F. Matsuda et al., "A newly developed robot suit Hybrid Assistive Limb facilitated walking rehabilitation after spinal surgery for thoracic ossification of the posterior longitudinal ligament: a case report," Case Reports in Orthopedics, vol. 2013, Article ID 621405, 4 pages, 2013.

[19] S. Kubota, T. Abe, K. Fujii et al., "Improvement of walking ability using Hybrid Assistive Limb training in a patient with severe thoracic myelopathy caused by ossification of the posterior longitudinal ligament - a case report," Journal of Spine, vol. 1, Supplement 7, 2016.

[20] K. Fujii, T. Abe, S. Kubota et al., "The voluntary driven exoskeleton Hybrid Assistive Limb (HAL) for postoperative training of thoracic ossification of the posterior longitudinal ligament: a case report," The Journal of Spinal Cord Medicine, vol. 40, no. 3, pp. 361-367, 2017.

[21] S. Kubota, T. Abe, H. Kadone et al., "Walking ability following Hybrid Assistive Limb treatment for a patient with chronic myelopathy after surgery for cervical ossification of the posterior longitudinal ligament," The Journal of Spinal Cord Medicine, pp. 1-9, 2017.

[22] M. Taketomi, Y. Shimizu, H. Kadone et al., "Hybrid Assistive Limb intervention in a patient with late neurological deterioration after thoracic myelopathy surgery due to ossification of the ligamentum flavum," Case Reports in Orthopedics, vol. 2018, Article ID 6171760, 10 pages, 2018.

[23] J. M. VanSwearingen, K. A. Paschal, P. Bonino, and J. F. Yang, "The modified Gait Abnormality Rating Scale for recognizing the risk of recurrent falls in community-dwelling elderly adults," Physical Therapy, vol. 76, no. 9, pp. 994-1002, 1996.

[24] P. L. Dittuno and J. F. Dittuno Jr, "Walking index for spinal cord injury (WISCI II): scale revision," Spinal Cord, vol. 39, no. 12, pp. 654-656, 2001.

[25] V. Dietz, "Proprioception and locomotor disorders," Nature Reviews Neuroscience, vol. 3, no. 10, pp. 781-790, 2002.

[26] S. Puentes, H. Kadone, S. Kubota et al., "Reshaping of gait coordination by robotic intervention in myelopathy patients after surgery," Frontiers in Neuroscience, vol. 12, p. 99, 2018.

[27] K. Jellema, C. C. Tijssen, and J. van Gijn, "Spinal dural arteriovenous fistulas: a congestive myelopathy that initially mimics a peripheral nerve disorder," Brain, vol. 129, no. 12, pp. 3150 3164, 2006.

[28] F. J. Rodriguez, B. A. Crum, W. E. Krauss, B. W. Scheithauer, and C. Giannini, "Venous congestive myelopathy: a mimic of neoplasia," Modern Pathology, vol. 18, no. 5, pp. 710-718, 2005.

[29] W. McKinley, A. Sinha, J. Ketchum, and X. Deng, "Comparison of rehabilitation outcomes following vascular-related and traumatic spinal cord injury," The Journal of Spinal Cord Medicine, vol. 34, no. 4, pp. 410-415, 2011.

[30] S. Behrens and A. Thron, "Long-term follow-up and outcome in patients treated for spinal dural arteriovenous fistula," Journal of Neurology, vol. 246, no. 3, pp. 181-185, 1999.

[31] A. E. Bond, G. Zada, I. Bowen, J. G. McComb, and M. D. Krieger, "Spinal arachnoid cysts in the pediatric population: report of 31 cases and a review of the literature," Journal of Neurosurgery. Pediatrics, vol. 9, no. 4, pp. 432-441, 2012.

[32] J. M. C. Van Dijk, K. G. TerBrugge, R. A. Willinsky, R. I. Farb, and M. C. Wallace, "Multidisciplinary management of spinal dural arteriovenous fistulas: clinical presentation and long- 
term follow-up in 49 patients," Stroke, vol. 33, no. 6, pp. 15781583, 2002.

[33] K. Onari, N. Akiyama, S. Kondo, A. Toguchi, H. Mihara, and T. Tsuchiya, "Long-term follow-up results of anterior interbody fusion applied for cervical myelopathy due to ossification of the posterior longitudinal ligament," Spine, vol. 26, no. 5, pp. 488-493, 2001.

[34] M. Iwasaki, Y. Kawaguchi, T. Kimura, and K. Yonenobu, "Long-term results of expansive laminoplasty for ossification of the posterior longitudinal ligament of the cervical spine: more than 10 years follow up," Journal of Neurosurgery: Spine, vol. 96, no. 2, pp. 180-189, 2002.

[35] M. Lee, A. R. Rezai, R. Abbott, D. H. Coelho, and F. J. Epstein, "Intramedullary spinal cord lipomas," Journal of Neurosurgery, vol. 82, no. 3, pp. 394-400, 1995.

[36] M. Y. Wang, S. Shah, and B. A. Green, "Clinical outcomes following cervical laminoplasty for 204 patients with cervical spondylotic myelopathy," Surgical Neurology, vol. 62, no. 6, pp. 487-492, 2004.

[37] A. Singh, D. Choi, and A. Crockard, "Use of walking data in assessing operative results for cervical spondylotic myelopathy: long-term follow-up and comparison with controls," Spine, vol. 34, no. 12, pp. 1296-1300, 2009.

[38] Z. Kadaňka, J. Bednarik, O. Novotny, I. Urbanek, and L. Dusek, "Cervical spondylotic myelopathy: conservative versus surgical treatment after 10 years," European Spine Journal, vol. 20, no. 9, pp. 1533-1538, 2011.

[39] D. Li, S. Y. Hao, Z. Wu, G. J. Jia, L. W. Zhang, and J. T. Zhang, "Intramedullary medullocervical ependymoma-surgical treatment, functional recovery, and long-term outcome," Neurologia Medico-Chirurgica, vol. 53, no. 10, pp. 663-675, 2013.

[40] T. Kaner, M. Sasani, T. Oktenoglu, B. Solmaz, A. C. Sarloglu, and A. F. Ozer, "Clinical analysis of 21 cases of spinal cord ependymoma: positive clinical results of gross total resection," Journal of Korean Neurosurgical Association, vol. 47, no. 2, pp. 102-106, 2010.

[41] Y. Shimizu, K. Nakai, H. Kadone et al., “The Hybrid Assistive Limb $^{\oplus}$ intervention for a postoperative patient with spinal dural arteriovenous fistula and chronic spinal cord injury: a case study," The Journal of Spinal Cord Medicine, pp. 1-8, 2017. 


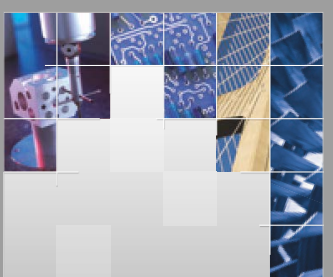

\section{Enfincering}
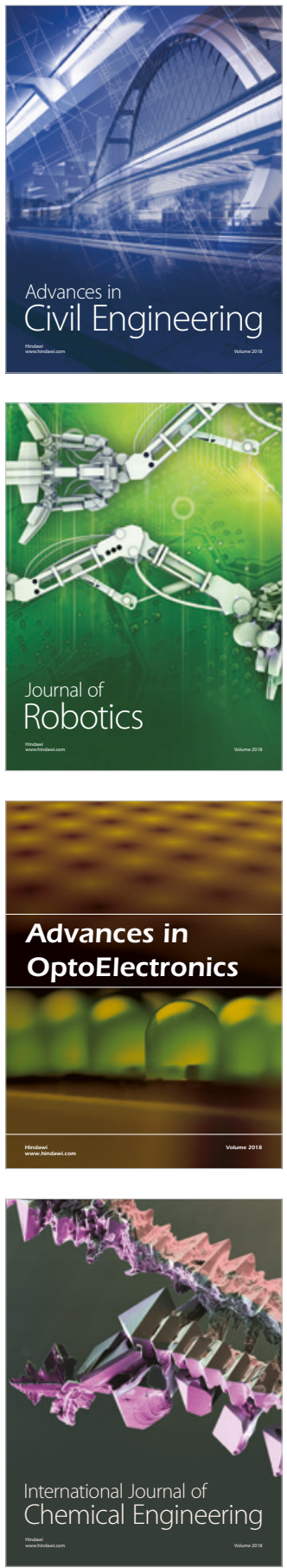

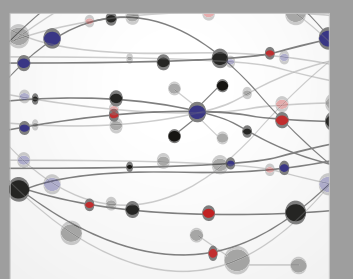

\section{Rotating \\ Machinery}

The Scientific World Journal

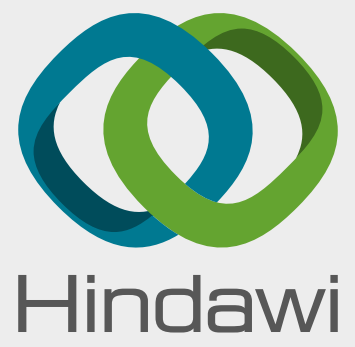

Submit your manuscripts at

www.hindawi.com
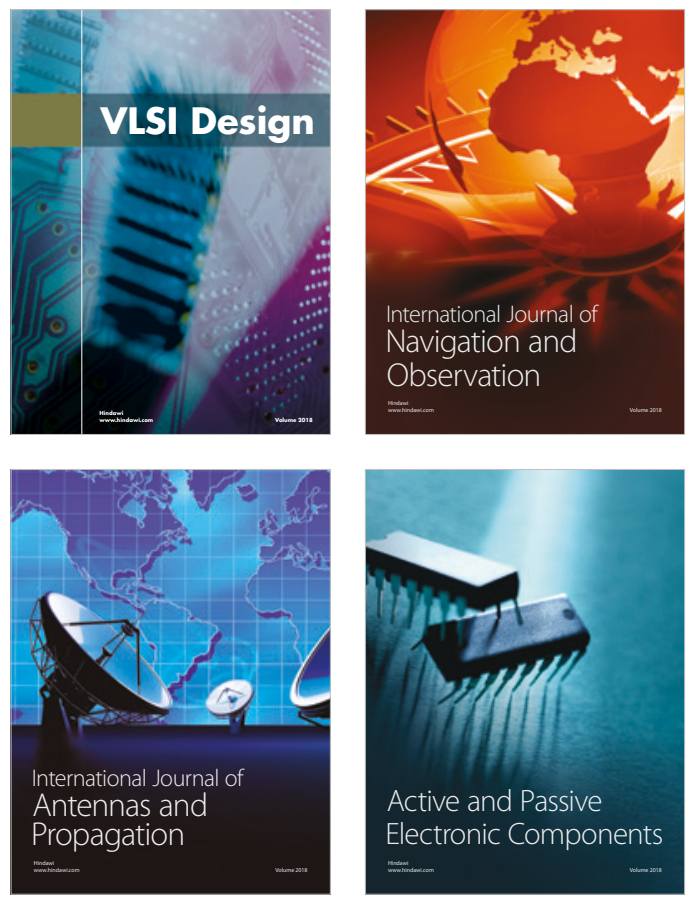
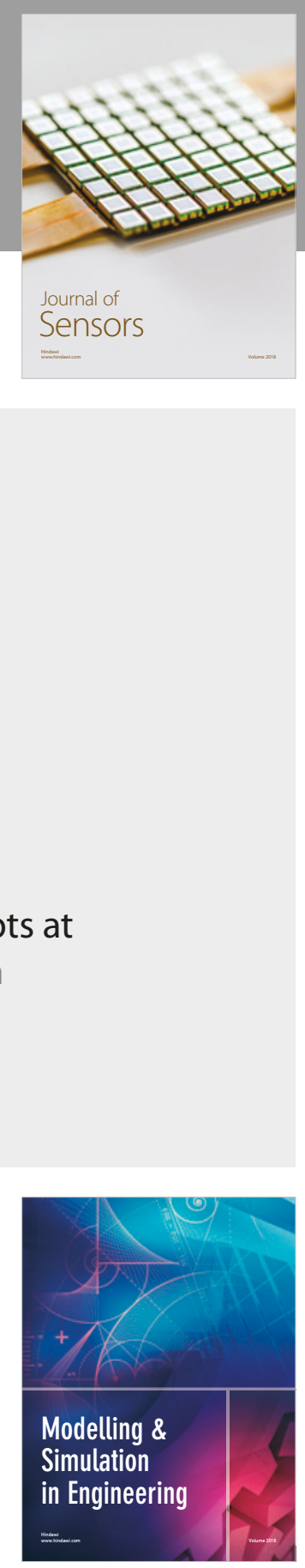

\section{Advances \\ Multimedia}
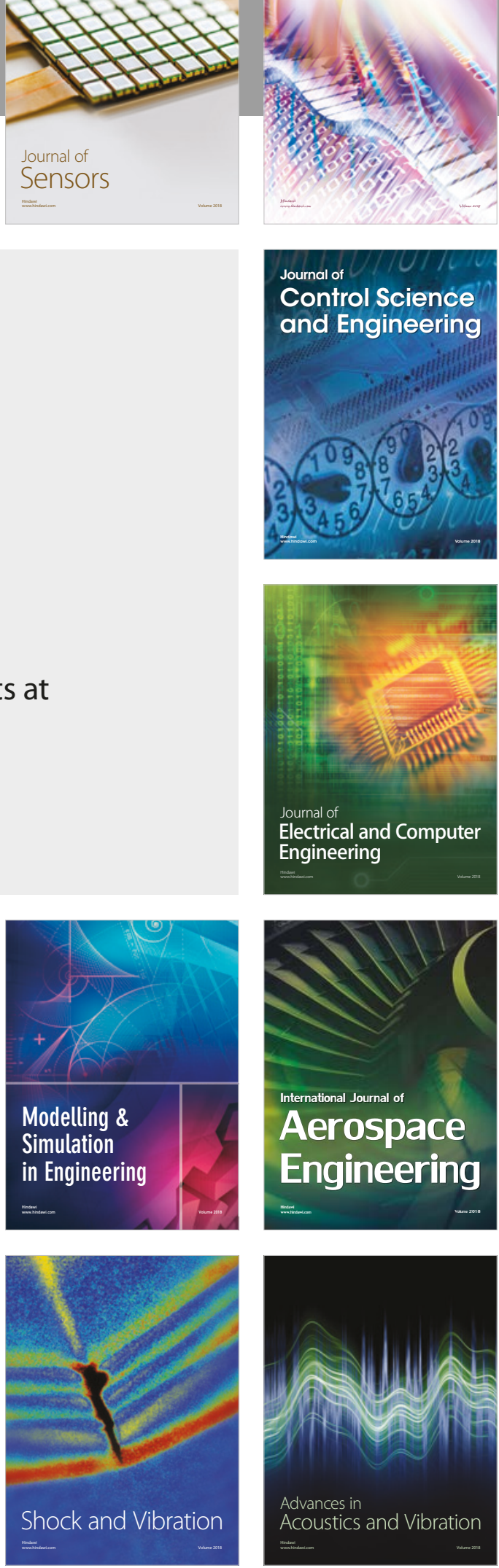